\title{
Microstructure and electrical conductivity of YSZ thin films prepared by pulsed laser deposition
}

\author{
Journal Article \\ Author(s): \\ Heiroth, Sebastian; Lippert, Thomas (D); Wokaun, Alexander; Döbeli, Max \\ Publication date: \\ 2008-11 \\ Permanent link: \\ https://doi.org/10.3929/ethz-b-000412198 \\ Rights / license: \\ $\underline{\text { In Copyright - Non-Commercial Use Permitted }}$ \\ Originally published in: \\ Applied Physics A 93(3), https://doi.org/10.1007/s00339-008-4689-6
}




\title{
Microstructure and electrical conductivity of YSZ thin films prepared by pulsed laser deposition
}

\author{
S. Heiroth · Th. Lippert • A. Wokaun · M. Döbeli
}

Received: 12 October 2007 / Accepted: 9 April 2008 / Published online: 13 June 2008

(C) Springer-Verlag 2008

\begin{abstract}
Yttria-stabilized zirconia (YSZ) is the most common solid electrolyte material used e.g. in ceramic fuel cells. Thin films of YSZ were deposited on $c$-cut sapphire single crystals by pulsed laser deposition using a $\mathrm{KrF}$ excimer laser focused on a polycrystalline $8 \mathrm{~mol} \% \quad \mathrm{Y}_{2} \mathrm{O}_{3}$-stabilized $\mathrm{ZrO}_{2}$ target. Depending on the substrate temperature and the oxygen background pressure during deposition, different microstructures are obtained. XRD and high-resolution SEM revealed the formation of dense amorphous films at room temperature. At $600^{\circ} \mathrm{C}$ preferentially (111) oriented polycrystalline films consisting of densely agglomerated nmsized grains of the cubic phase resulted. Grain size and surface roughness could be controlled by varying the oxygen background pressure. RBS and PIXE evidenced congruent transfer only for a low number of pulses, indicating a dynamical change of the target stoichiometry during laser irradiation. The in-plane ionic conductivity of the as-deposited crystalline films was comparable to bulk YSZ. The conductivity of initially amorphous YSZ passes a maximum during the crystallization process. However, the relative changes remain small, i.e. no significant enhancement of ionic conductivity related to the formation of a nanocrystalline microstructure is found.
\end{abstract}

PACS 81.15.Fg $\cdot 82.45 . \mathrm{Xy}$

S. Heiroth $\cdot$ Th. Lippert $(\bowtie) \cdot A$. Wokaun

Paul Scherrer Institut, 5232 Villigen PSI, Switzerland

e-mail: thomas.lippert@psi.ch

M. Döbeli

Ion Beam Physics, Paul Scherrer Institut and ETH Zurich,

8093 Zurich, Switzerland

\section{Introduction}

Fluorite-type zirconia may be doped with a variety of aliovalent oxides such as $\mathrm{CaO}, \mathrm{Sc}_{2} \mathrm{O}_{3}, \mathrm{Gd}_{2} \mathrm{O}_{3}$ or $\mathrm{Y}_{2} \mathrm{O}_{3}$ to yield solid solutions that stabilize the cubic structure. Insertion of the lower valent cations is compensated by formation of oxygen vacancies resulting in ionic conduction at elevated temperatures via a thermally activated hopping mechanism. Due to their additional chemical stability in oxidizing as well as reducing atmospheres these materials represent the most widely employed solid electrolytes in high temperature electrochemical devices such as gas sensors, ionic membranes or solid oxide fuel cells (SOFCs) [1]. Approaches to improve device performance by lowering the internal resistance allowing operation at lower temperatures aim at processing these materials in the form of thin films, i.e. $<1 \mu \mathrm{m}$ thickness, as well as microstructural enhancement of the transport properties [2]. Recently, a possible enhancement of ionic conductivity by nanoscale effects, e.g. nanocrystalline microstructure, has been reported by Kosacki et al. [3, 4] but could not be verified by Joo and Choi [5]. In the present work thin films of yttria-stabilized zirconia (YSZ) with amorphous to highly textured crystalline microstructures of controlled chemical composition were deposited by pulsed laser deposition (PLD) and their electrical properties were analysed. Prydes et al. demonstrated the adaptability of PLD to uniform large-area coating as prerequisite to industrial application [6]. Amorphous YSZ was studied to elucidate possible nanoscale effects during crystallization using time-resolved conductivity measurements.

\section{Experimental}

Thin films (60-450 nm) of YSZ have been deposited on $c$ cut sapphire single crystals $\left(10 \times 10 \times 0.5 \mathrm{~mm}^{3}\right)$ by pulsed 
laser deposition using a focused $\mathrm{KrF}$ laser $(\lambda: 248 \mathrm{~nm}$, $\tau: 20 \mathrm{~ns}, 10 \mathrm{~Hz}$ ) beam yielding a fluence of $4.0 \mathrm{~J} / \mathrm{cm}^{2}$ on the rotatable target. The cylindrical target ( $\varnothing: 12.7 \mathrm{~mm}$, length: $50 \mathrm{~mm}$ ) was prepared by uniaxial pressing at $4.0 \mathrm{kbar}$ and subsequent sintering for $10 \mathrm{~h}$ at $1600^{\circ} \mathrm{C}$ from $8 \mathrm{~mol} \% \mathrm{Y}_{2} \mathrm{O}_{3}$ doped $\mathrm{ZrO}_{2}$ (8YSZ) powder. The substrate was mounted on a rotatable and heatable sample holder and positioned at a distance of $50 \mathrm{~mm}$ to the target. The depositions were conducted in an oxygen background $\left(p_{\mathrm{O} 2}\right)$ of $10^{-1}$ to $10^{-3}$ mbar established after evacuation of the vacuum chamber to a base pressure of $\sim 2 \times 10^{-5}$ mbar at room temperature and $600^{\circ} \mathrm{C}$ substrate temperature. Substrate pretreatment consisted of rinsing with methanol and acetone, drying in a $\mathrm{N}_{2}$ jet and subsequent $1 \mathrm{~h}$ annealing at $1000^{\circ} \mathrm{C}$ in air to obtain clean, well-defined atomically smooth terraced surfaces [7].

Film thicknesses were derived from profilometry using a Dektak 8 system and Rutherford backscattering spectra. The microstructure was investigated by high resolution scanning electron microscopy using a Zeiss Supra VP55. Samples were sputtered with $\sim 10 \mathrm{~nm}$ carbon prior to imaging to avoid charging. Crystallographic phase composition was analysed on a Siemens D500 diffractometer with BraggBrentano geometry using $\mathrm{Cu} \mathrm{K}_{\alpha}$ radiation. Surface topography of films and substrate preparation were monitored by atomic force microscopy (AFM) employing a Nanoscope IIIa with $\mathrm{Si}_{3} \mathrm{~N}_{4}$ cantilevers $(k: 0.06 \mathrm{~N} / \mathrm{m})$ in contact mode.

Rutherford backscattering spectroscopy (RBS) and particle-induced X-ray emission (PIXE) using $2 \mathrm{MeV}^{4} \mathrm{He}$ ions and $3 \mathrm{MeV}$ protons as projectiles served as analytical tools to determine the chemical composition of the films. The RUMP software was utilized for RBS data analysis.

Electrical resistivity measurements were conducted in a two-point d.c. probe configuration after sputtering of $0.5 \times$ $10.0 \mathrm{~mm}^{2}$ Pt electrodes which were separated $5.0 \mathrm{~mm}$ from each other, on top of the films and contacting with Pt wires. Resistance was measured between room temperature and $680^{\circ} \mathrm{C}$ at a heating/cooling rate of $3 \mathrm{~K} / \mathrm{min}$ as well as time dependently at a fixed temperature using a Keithley 2400 source meter.

\section{Results and discussion}

\subsection{Microstructure}

The phase composition of the YSZ thin films has been determined by X-ray diffraction (XRD). In Fig. 1 XRD patterns of films obtained at room temperature and at a substrate temperature of $600^{\circ} \mathrm{C}$ during deposition are shown in comparison to bulk 8YSZ in the form of fine-grained powder (grain size: $21.4 \pm 1.4 \mathrm{~nm}$ ). The reflexes of the bulk sample are in agreement with reference data for the cubic

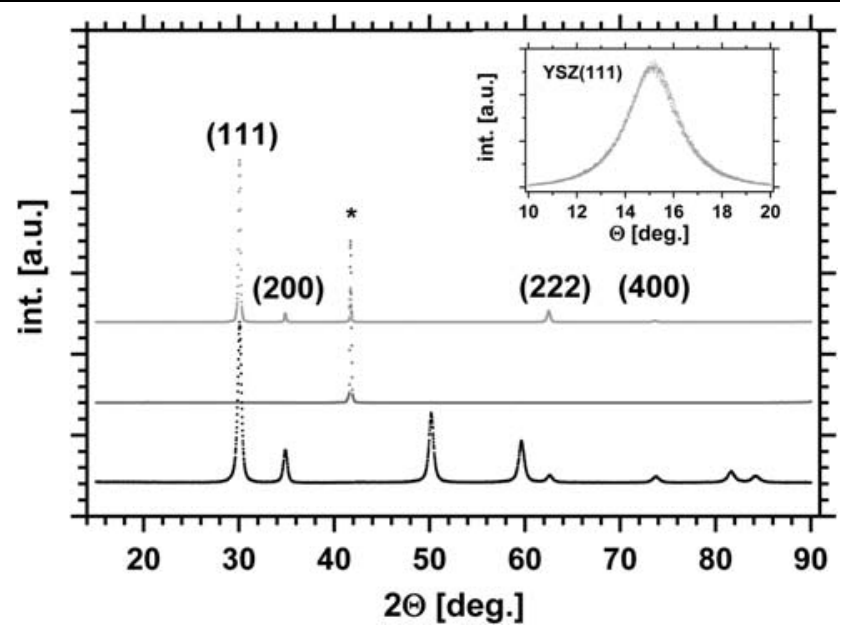

Fig. 1 XRD patterns, normalized to the most intense reflection, of 8YSZ bulk powder (bottom) and YSZ thin films deposited on sapphire $(0001)$ at $20^{\circ} \mathrm{C}$ (middle) and $600^{\circ} \mathrm{C}$ (top) at a $p_{\mathrm{O} 2}$ of $10^{-2} \mathrm{mbar}$; the substrate (006) reflection is marked with an asterisk. The inset shows the rocking curve of the (111) reflection of the film deposited at $600^{\circ} \mathrm{C}$

fluorite structure expected for this dopant level. The absence of any reflections in addition to the substrate (006) reflection in the case of the films deposited at room temperature reveals their amorphous nature. On the contrary, the films deposited at elevated temperature show further peaks of the cubic YSZ phase illustrating their polycrystallinity. A preferential (111) orientation with a variable fraction of additional (100) orientation was found, which is consistent with recently published results [5]. The relatively wide FWHM of $2.55^{\circ}$ of the (111) rocking curve, displayed as inset in Fig. 1, confirms the imperfect epitaxy and polycrystalline nature. No secondary phases were detected for all studied films.

The cross-sectional scanning electron microscopy (SEM) micrograph of a film deposited at $20^{\circ} \mathrm{C}$ in Fig. 2a appears dense and fairly uniform without any visible fine structure, consistent with the isotropic amorphous nature determined by XRD. A higher deposition temperature results in a film consisting of densely agglomerated $\mathrm{nm}$-sized grains emphasized by the arrow in Fig. 2b. The sharp vertical features, visible in the film deposited at $600^{\circ} \mathrm{C}$, indicated by the dashed line may be attributed to the mechanical cleavage. It is noteworthy to mention that the film/substrate interface highlighted by the horizontal dashed line in Fig. 2a, appears remarkably sharp, without any visible voids in both cases. Simple Scotch tape tests confirmed an adequate adhesion between film and substrate. Moreover, the observed dense nature of the deposited films is an indispensable property to achieve gas impermeability required for solid electrolyte purposes. A major challenge in this context represents the complete elimination of $\mu \mathrm{m}$-sized particulates which are incorporated into the film during the PLD process. 

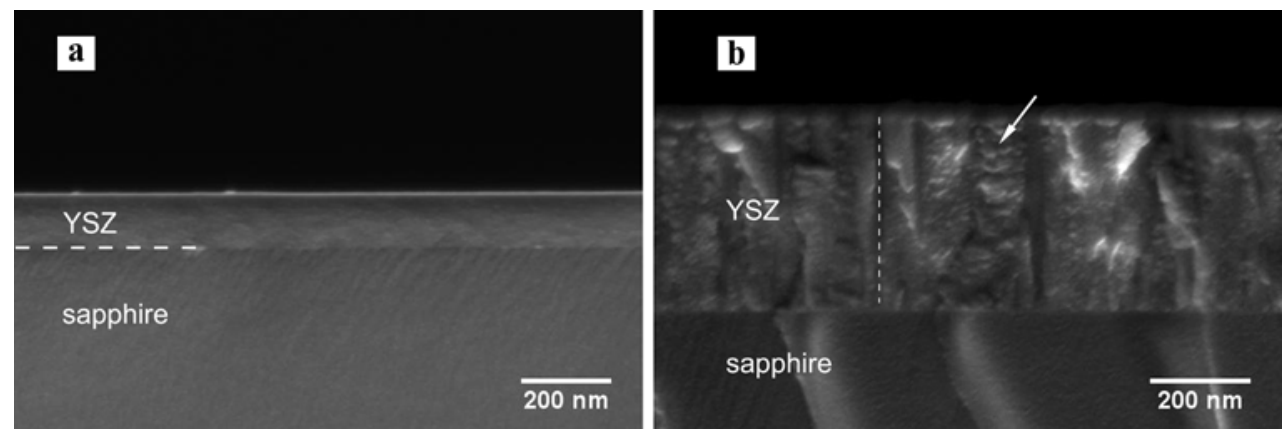

Fig. 2 Cross-sectional SEM micrographs of YSZ thin films on sapphire(0001): (a) deposited at $20^{\circ} \mathrm{C}$ and a $p_{\mathrm{O} 2}$ of $10^{-2}$ mbar, the dashed line emphasizes the YSZ/sapphire interface, (b) deposited at $600^{\circ} \mathrm{C}$ and a $p_{\mathrm{O} 2}$ of $10^{-2}$ mbar, the dashed line is used to emphasize a cleav- age artifact while the arrow indicates a region of agglomerated grains. The thickest film of $\sim 450 \mathrm{~nm}$ was chosen for illustration here since it displayed the characteristic features best

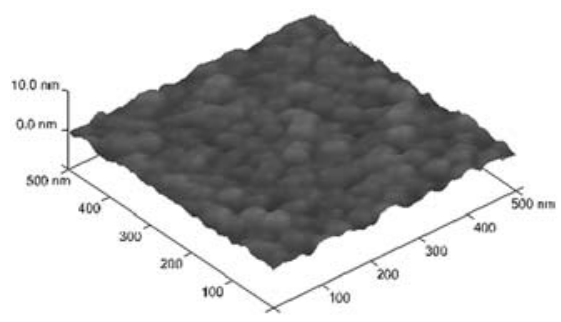

$R_{\mathrm{q}} 6.4 \pm 0.1 \AA$

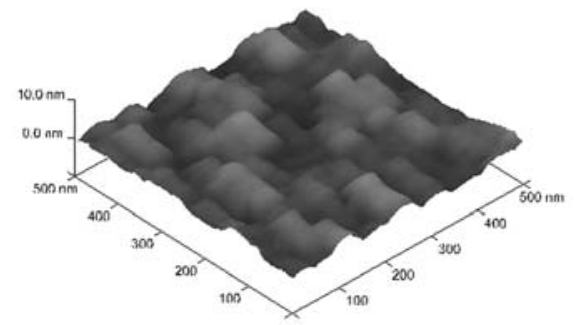

$R_{\mathrm{q}:} 13.5 \pm 0.5 \AA$

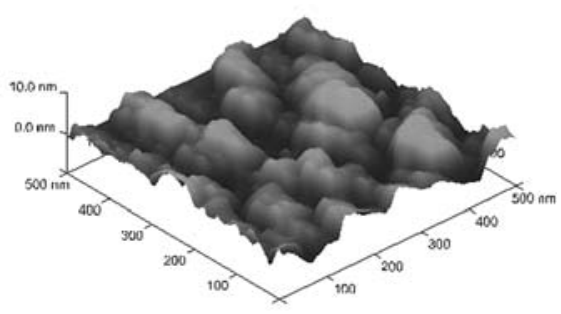

$R_{\mathrm{q}} 27.5 \pm 0.4 \AA$

c

a

b

Fig. 3 Topographical AFM images and corresponding rms roughness of YSZ thin films (thickness of $425 \pm 25 \mathrm{~nm}$ ) deposited at a $T$ of $600^{\circ} \mathrm{C}$ and a $p_{\mathrm{O} 2}$ of (a) $10^{-3} \mathrm{mbar}$, (b) $10^{-2} \mathrm{mbar},(\mathbf{c}) 10^{-1} \mathrm{mbar}$

The topographical AFM images in Fig. 3 illustrate the impact of modifying the oxygen background pressure on the microstructure of YSZ thin films. Surface roughness and maximum grain dimensions increase with $p_{\mathrm{O} 2}$. At low oxygen pressure (Fig. 3a) the grains are small $(20-30 \mathrm{~nm})$ and exhibit a narrow size distribution. Figure $3 \mathrm{~b}$ reveals a platelet-like morphology with grain dimensions in the range of $50-80 \mathrm{~nm}$ for $10^{-2}$ mbar. At $10^{-1}$ mbar (Fig. 3c) a bimodal grain size distribution with large grains of up to $120 \mathrm{~nm}$ lateral extension interspersed with small grains of about $20-30 \mathrm{~nm}$ is observed. The mean free pathway of the ablated species is several times larger than the target to substrate distance at $10^{-3}$ mbar. This suggests that almost no collisions between $\mathrm{O}_{2}$ molecules and ablated species occur, resulting in a high kinetic energy and narrow distribution of incident angles of the species arriving at the surface, yielding smooth and uniform surfaces. With increasing pressure scattering has to be taken into account, resulting in a loss of kinetic energy available to nucleation and surface diffusion of the adsorbed species. Additionally, a wider distribution of incident angles induces shadowing effects on the growing film [8]. Both effects contribute to rougher surfaces with larger features.

\subsection{Chemical composition}

The chemical compositions of the YSZ thin films have been analysed by a combination of RBS and PIXE (Fig. 4) since the electrical properties of the material are intimately coupled to its stoichiometry. RBS data analysis yielded the (Y/Zr):O ratios. As Fig. 4 illustrates the $\mathrm{Y}$ and $\mathrm{Zr}$ signals may not be resolved by RBS due to almost identical atomic masses differing just by $\sim 1 \mathrm{u}$ for the main isotopes. The $\mathrm{Y} / \mathrm{Zr}$ ratio was calculated from the intensity ratio of the $\mathrm{K}_{\alpha}$ lines in the X-ray emission spectrum obtained by PIXE using tabulated values for branching ratios, fluorescence yields and ionization cross sections [9]. Table 1 summarizes the derived stoichiometries for a selection of films. Zirconia and yttria thin-film standards proved that absorption effects could be neglected. About 1.0-1.5 wt.\% Hf was detected as impurity in the RBS spectra of the films. Laser-assisted ICPMS confirmed a Hf concentration of $1.28 \pm 0.15$ wt. $\%$ in the 8YSZ target. Hafnium is commonly present in commercial $\mathrm{Zr}$ compounds, unless purified for neutron reflection purposes, due to the highly similar chemical properties of the elements. Therefore, its impact on the electrical properties is considered to be negligible compared to e.g. siliceous impurities [10]. The results summarized in Table 1 reveal a significantly increasing oxygen deficiency in the 
Table 1 Chemical composition normalized to the sum of cationic mole fractions for selected YSZ thin films

\begin{tabular}{lllllll}
\hline Thickness $[\mathrm{nm}]$ & $T\left[{ }^{\circ} \mathrm{C}\right]$ & $p_{\mathrm{O} 2}[\mathrm{mbar}]$ & $x(\mathrm{Zr})$ & $x(\mathrm{Y})$ & $x(\mathrm{Hf})$ & $x(\mathrm{O})$ \\
\hline $407.8 \pm 8.9$ & 600 & $10^{-3}$ & $0.845 \pm 0.002$ & $0.145 \pm 0.002$ & $0.010 \pm 0.001$ & $1.750 \pm 0.088$ \\
$452.0 \pm 9.9$ & 600 & $10^{-2}$ & $0.840 \pm 0.002$ & $0.150 \pm 0.002$ & $0.010 \pm 0.001$ & $1.870 \pm 0.094$ \\
$419.2 \pm 9.3$ & 600 & $10^{-1}$ & $0.847 \pm 0.004$ & $0.141 \pm 0.004$ & $0.012 \pm 0.001$ & $1.916 \pm 0.096$ \\
$148.1 \pm 3.5$ & 600 & $10^{-2}$ & $0.831 \pm 0.003$ & $0.159 \pm 0.003$ & $0.010 \pm 0.001$ & $1.915 \pm 0.096$ \\
$149.4 \pm 3.7$ & 20 & $10^{-2}$ & $0.832 \pm 0.004$ & $0.160 \pm 0.004$ & $0.008 \pm 0.001$ & $1.904 \pm 0.095$ \\
\hline
\end{tabular}

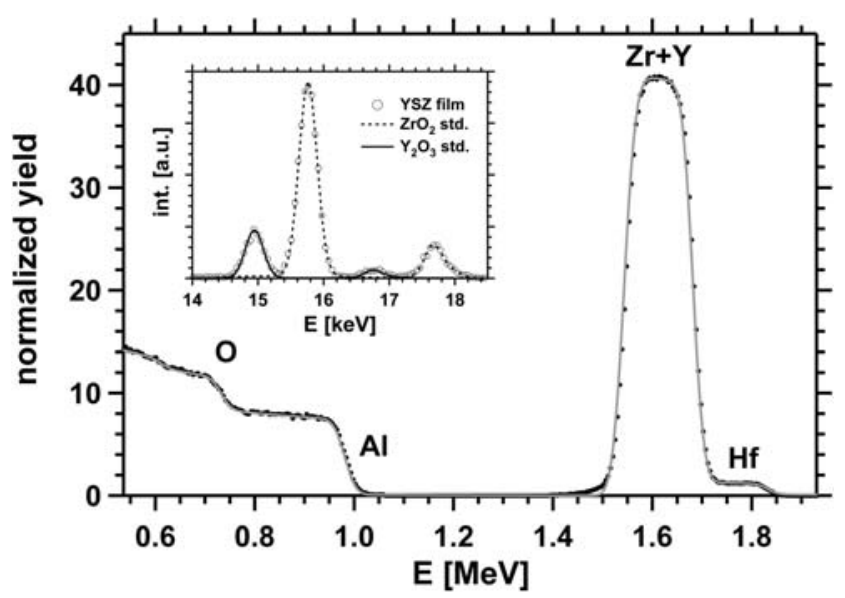

Fig. 4 Rutherford backscattering and corresponding PIXE (inset) spectra for a $\sim 150$-nm-thick YSZ film deposited at a $T$ of $20^{\circ} \mathrm{C}$ with a $p_{\mathrm{O} 2}$ of $10^{-2}$ mbar

YSZ films with decreasing oxygen pressure for about 400nm-thick films. Moreover, a reduced Y content compared to the target of 16 at.\% was observed, as previously reported by Joo and Choi for thicker films [5]. Contrarily, almost congruent transfer was observed for films with lower thickness (Table 1). A local change of the color from white to black during laser irradiation, which is reversible by annealing at $200^{\circ} \mathrm{C}$ in air, suggests a dynamical laser induced oxygen deficiency of the target, which is reflected in the composition of the resulting film. Larger oxygen deficiencies may be expected for an increased number of pulses, i.e. thicker films and for lower oxygen pressure.

Electrical characterization was restricted to the thinner films since a meaningful comparison of electrical properties among samples of different microstructures or between thin films and bulk relies on an identical stoichiometry.

\subsection{Electrical properties}

The in-plane conductivity of YSZ thin films was investigated by the two-point d.c. probe technique, which is applicable since the contact resistances are negligible compared to the film resistance. Sapphire served as insulating support due to its chemical inertness and low conductivity, being about three orders of magnitude smaller com-

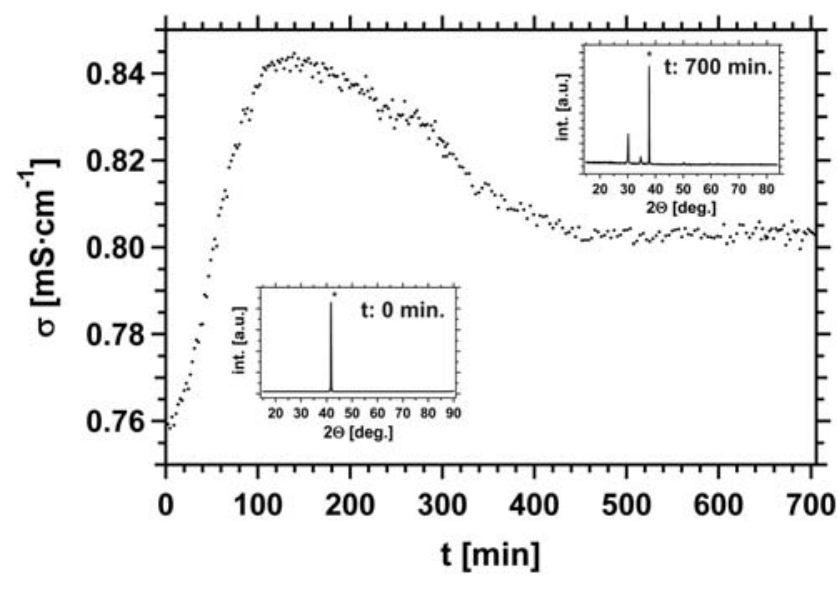

Fig. 5 Transient d.c. electrical conductivity (in-plane) of an initially amorphous YSZ film $\left(T: 20^{\circ} \mathrm{C}, p_{\mathrm{O} 2}: 10^{-2} \mathrm{mbar}\right)$ as a function of holding time $t$ at $580^{\circ} \mathrm{C}$ in air, insets: XRD patterns before and after measurement (the substrate reflection is marked with an asterisk)

pared to 8YSZ [11]. So far, investigations are focused on stable (nano)crystalline microstructures, which would be required for application [3, 5, 11]. Metastable amorphous materials were disregarded since they crystallize at elevated temperatures. However, the time scale of the crystallization process is directly correlated to the grain size. Therefore, time-dependent electrical measurements of amorphous films under crystallization conditions provide a way to probe the influence of grain size on the electrical transport properties. Figure 5 depicts the electrical conductivity of an initially amorphous YSZ film as a function of time at a fixed temperature of $580^{\circ} \mathrm{C}$. During the first $120 \mathrm{~min}$ a steep increase of conductivity to a maximum of $0.845 \mathrm{mS} / \mathrm{cm}$ followed by a subsequent slow decrease to a constant value of $\sim 0.805 \mathrm{mS} / \mathrm{cm}$, reached after approximately $420 \mathrm{~min}$, was obtained. The XRD pattern taken after $700 \mathrm{~min}$ at $580^{\circ} \mathrm{C}$ shows a transition to a polycrystalline microstructure with an average grain size of approx. $20 \mathrm{~nm}$. Figure 5 suggests the existence of an optimum grain size with the highest electrical conductivity during crystallization. Nevertheless, the relative change of conductivity remains small, possibly due to the onset of crystallization during heating. The Arrhenius plot in Fig. 6 reveals that the absolute conductivity of this annealed, initially amorphous film is about half 


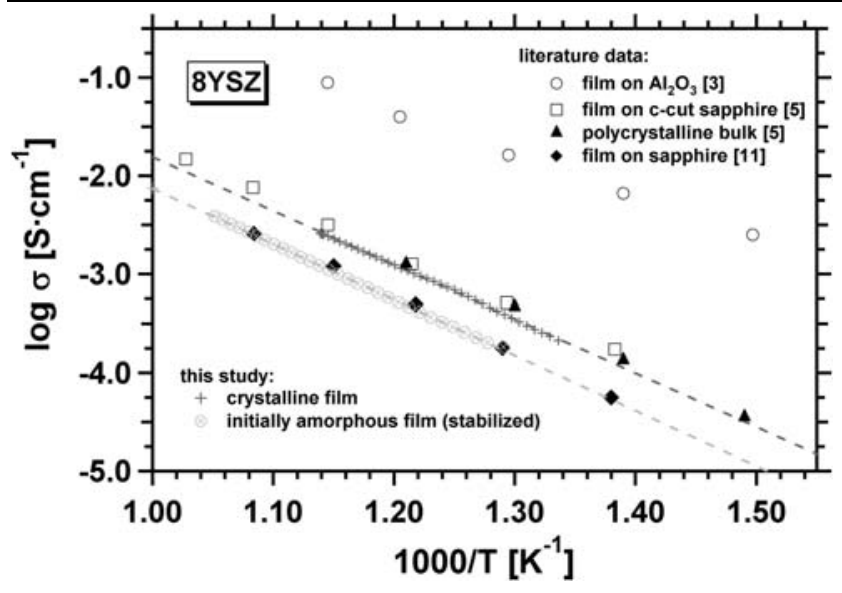

Fig. 6 Temperature-dependent d.c. electrical conductivity of a crystalline $\left(T: 600^{\circ} \mathrm{C}, p_{\mathrm{O} 2}: 10^{-2} \mathrm{mbar}\right) \mathrm{YSZ}$ film and an initially amorphous $\left(T: 600^{\circ} \mathrm{C}, p_{\mathrm{O} 2}: 10^{-2} \mathrm{mbar}\right) \mathrm{YSZ}$ thin film after keeping the film at $580^{\circ} \mathrm{C}$ for $700 \mathrm{~min}$; literature data are included for comparison

an order of magnitude lower than for the as-deposited crystalline YSZ film with an average grain size of $\sim 40 \mathrm{~nm}$. The activation energies of $1.13 \pm 0.02$ and $1.08 \pm 0.02 \mathrm{eV}$ are close to reported values $[5,11]$. The lower conductivity and higher activation energy of the previously amorphous films may originate from an incomplete crystallization at the annealing temperature of $580^{\circ} \mathrm{C}$. In summary, no evidence was found for a significant enhancement of ionic conductivity by a nanocrystalline (grain size up to $\sim 40 \mathrm{~nm}$ ) microstructure as reported by Kosacki et al. [3]. The comparison to literature conductivity data $[3,5,11]$, included in Fig. 6, reveals that all conductivity data are close to ionic conductivities commonly reported for YSZ bulk and thin-film samples.

\section{Conclusions}

Modification of substrate temperature and oxygen pressure in pulsed laser deposition of YSZ can be utilized to control the microstructure of the resulting film. Dense amorphous films are accessible at room temperature while at an elevated temperature of $600^{\circ} \mathrm{C}$ thin films consisting of densely agglomerated crystallites with preferential (111) orientation are obtained on $c$-cut sapphire substrates. The grain size and surface roughness increase with increasing oxygen pressure. Congruent transfer is restricted to a low number of pulses $(<30000)$, i.e. for films with a thickness $<200 \mathrm{~nm}$, since the target stoichiometry changes dynamically with laser irradiation. The ionic conductivity of as-deposited amorphous YSZ films is at least half an order of magnitude lower than for pulsed laser deposited polycrystalline films which exhibit electrical properties similar to bulk YSZ. No significant nanoscale-related enhancement of ionic conductivity could be ascertained during the transition from amorphous to nanocrystalline, which supports recent experimental results [5].

Acknowledgements The authors would like to thank Patrick Ruch for assistance with the FE-SEM, Ruggero Frison for preparation of the ceramic target, Dr. Anna Infortuna (ETH Zurich) for her support concerning the d.c. electrical characterization setup and Dr. Joachim Koch (ETH Zurich) for performing the laser-assisted ICPMS analysis. The project is part of the program 'Ceramic thin films without sintering' (NANCER) funded by the competence center of material science and technologies (CCMX) of the ETH board, Switzerland. Additional financial support provided by the ESF within the DYNA program is gratefully acknowledged.

\section{References}

1. N.Q. Minh, J. Am. Ceram. Soc. 76, 563 (1993)

2. D. Perednis, L.J. Gauckler, Solid State Ionics 166, 229 (2004)

3. I. Kosacki, T. Suzuki, V. Petrovsky, H.U. Anderson, Solid State Ionics 136, 1225 (2000)

4. I. Kosacki, C.M. Rouleau, P.F. Becher, J. Bentley, D.H. Lowndes, Solid State Ionics 176, 1319 (2005)

5. J.H. Joo, G.M. Choi, Solid State Ionics 177, 1053 (2006)

6. N. Pryds, B. Toftmann, J.B. Bilde-Sorensen, J. Schou, S. Linderoth, Appl. Surf. Sci. 252, 4882 (2006)

7. M. Yoshimoto, T. Maeda, T. Ohnishi, H. Koinuma, O. Ishiyama, M. Shinohara, M. Kubo, R. Miura, A. Miyamoto, Appl. Phys. Lett. 67, 2615 (1995)

8. J.A. Thornton, J. Vac. Sci. Technol. A: Vac. Surf. Films 4, 3059 (1986)

9. S.A.E. Johansson, J.L. Campbell, PIXE: A Novel Technique for Elemental Analysis (Wiley, New York, 1988)

10. M. Aoki, Y.M. Chiang, I. Kosacki, I.J.R. Lee, H. Tuller, Y.P. Liu, J. Am. Ceram. Soc. 79, 1169 (1996)

11. T. Petrovsky, H.U. Anderson, V. Petrovsky, Mater. Res. Soc. Symp. Proc. 756, EE4.7.1 (2003) 